\title{
Potencial de antagonismo de isolados de Trichoderma sp. contra o isolados de Fusarium sp., in vitro
}

\section{Potential of isolated antagonism of Trichoderma against isolated from Fusarium sp., in vitro}

Charles Anthony Hoffmann ${ }^{1}$, Líllian França Borges Chagas ${ }^{2}$, Diego Pereira da Silva ${ }^{3}$, Aloísio Freitas Chagas Junior ${ }^{4}$, Gessiel Newton Scheidt ${ }^{5}$

Resumo - O uso discriminado de agrotóxicos acarreta em uma grande prejuízo a saúdes das pessoas e do meio ambiente. O uso de novos métodos de combate a pragas se faz necessário para o equilíbrio da cadeia produtiva. A utilização de microrganismos no combate a pragas se faz como uma boa alternativa. $O$ trabalho objetivou-se em avaliar o potencial de antagonismo de isolados de Trichoderma sp. contra o patógeno Fusarium sp. in vitro. Para isso foi utilizado os métodos de confronto direto, pareamento de culturas e de metabólitos voláteis. Os experimentos foram realizados na incubadora de empresas da Universidade Federal do Tocantins - UFT Campus de Gurupi, seguiram com três repetições. Foram testados 15 isolados do antagonista em confronto direto com o patógeno e os mesmos isolados e patógeno foram testados em metabólitos voláteis ambos utilizando o meio de cultura BDA. Todos os isolados apresentaram antagonismo in vitro contra o patógeno.

Palavras-chave: controle biológico, metabólitos voláteis, patógeno

\begin{abstract}
The use of pesticides broken leads to a great loss to health of people and the environment. The use of new methods for the control of pests is need to balance the supply chain. The use of microorganisms for combating pests is a good alternative. The work aimed in evaluating the potential of Trichoderma $s p$. isolates of antagonism against the pathogen Fusarium sp. in vitro. For this, we used the direct confrontation of methods, pairing cultures and volatile metabolites. The experiments were performed in the business incubator of the University of Tocantins - UFT Campus Gurupi, followed with three replications. 15 isolates of the antagonist were tested in direct confrontation with the pathogen and the same pathogen isolated and volatile metabolites were tested in both using the PDA culture medium. All isolates showed in vitro antagonism against the pathogen.
\end{abstract}

Keywords: Biological control, volatile metabolites, pathogen

\footnotetext{
*Autor para correspondência

Recebido para publicação em 27/11/2014; aprovado em 25/02/2015

${ }^{1}$ Cirurgião dentista pós-graduação no mestrado em biotecnologia pela Universidade Federal do Tocantins - TO. E-mail: hoffmann26@ outlook.com

${ }^{2}$ Engenheira Agrônoma pós-graduação no doutorado em produção vegetal pela Universidade Federal do Tocantins - TO. E-mail: lillianfb@ hotmail.com

${ }^{3}$ Engenheiro de Alimentos mestre em biotecnologia pela Universidade Federal do Tocantins - TO. E-mail: diegouft@ outlook.com

${ }^{4}$ Engenheiro Agrônomo Dr., professor do curso de pós-graduação em biotecnologia pela Universidade Federal do Tocantins-TO. E-mail: chagasjrf@uft.edu.br

${ }^{5}$ Biologo Dr., professor do curso de pós-graduação em biotecnologia pela Universidade Federal do Tocantins - TO. E-mail: gessielscheidt@ yahoo.com.br
} 


\section{INTRODUÇÃO}

Com base nas necessidades e do aumento da produção de diversos produtos, principalmente alimentos do cotidiano da humanidade, novas meios de produção e cultivo são de suma importância para o futuro da segurança e do abastecimento alimentar. As pesquisas biotecnológicas que buscam novos insumos externam a grande necessidade e preocupação por parte dos pesquisadores e produtores para o avanço do cultivo de uma série de produtos essenciais na cadeia produtiva. Novos meios de combate a pragas e doenças que possuem características menos hostis a saúde humana e o meio ambiente como os bioinseticidas, fungicidas são indispensáveis para o desenvolvimento sustentável tão desejado da produção (MARTINS, 2004; BORÉM, 2005; EMBRAPA 2009; BRASIL, 2012)

A sociedade está cada vez mais interessada em uma agricultura que possa proporcionar qualidade de vida aos consumidores, garantido alimentos com os atributos adequados à saúde humana, livre de resíduos de natureza química, biológica ou física, ou de qualquer outra substância que possa acarretar problemas à população e com comprovada sustentabilidade ambiental (PESSANHA \& WILKINSON, 2003).

Os fungos do gênero Trichoderma são característicos do solo e nas raízes das plantas. São saprófitos e utilizados como agentes de controle biológico e produtores de uma série de enzimas para uso industrial (BETIOL \& MORANDI, 2009). - Com o uso indiscriminado de agrotóxicos aumentam as taxas de doenças relacionadas com resíduos químicos ingeridos pelo ser humano, o controle fitopatogênico a base de pesticidas biológicos se torna um relevante alternativa para diminuir os riscos para a saúde humana (GRIGOLETTI JÚNIOR et al., 2000; PERES et al., 2007).

Em todo o mundo a uma crescente preocupação com os problemas ambientais decorrentes das diversas atividades humanas, incluindo a agricultura (ANDRADE \& NOGUEIRA, 2005). E isso se resulta na busca por tecnologias de produção rentáveis, socialmente justas e ecologicamente corretas (MELLO \& SILVA, 2007). Para responder a esta demanda, a pesquisa científica tem avançado no desenvolvimento de soluções apoiadas em processos biológicos naturais (MARQUES et al., 2014). O controle biológico se caracteriza como uma alternativa cada vez mais importante, uma vez que, na agricultura convencional, utilizado de forma complementar, contribui para a redução do uso dos agrotóxicos, enquanto na agricultura orgânica, inserese em substituição à estes produtos (PERES et al., 2007; BONFIM, et al., 2010; BONETT, et al., 2013).

O grupo Trichoderma está entre os microrganismos mais resistentes às toxinas e produtos químicos naturais e sintetizados pelo homem (HARMAN et al., 2004). São capazes de degradar compostos orgânicos e inorgânicos, como os hidrocarbonetos e pesticidas (BONFIM, et al.
2010). Protegem e colonizam o sistema radicular disponibilizando a solubilização de nutrientes para as plantas (BONFIM, et al., 2010; OLIVEIRA et al., 2012). Essas descobertas auxiliam o entendimento do papel do grupo Trichoderma para sua utilização na agricultura (BETIOL, W. \& MORANDI M. A. B., 2009; JESUS, et al., 2011).

O grupo Trichoderma se apresenta como fungos filamentosos comum em áreas tropicais e subtropicais, mas podem habitar climas frios (ETHUR, 2006). As espécies mais comuns são $F$. solani, Fusarium oxysporum, F. moniliforme e F. verticillioidis (FREITAS, 2010). O Fusarium tem um crescimento rápido em ágar com temperatura média de $25^{\circ} \mathrm{e}$ assim produz uma colônia felpuda e dependendo da espécie sua cor pode mudar entre incolor, roxo, alaranjado à avermelhado e marrom (FISCHER, 1982; HOOG, 2000).

$\mathrm{O}$ grupo de fungos compreendido pelo Fusarium são patógenos que destroem as raízes de plantas como a soja, o abacaxi, o tomateiro, o pepineiro, o maracujazeiro, o feijão, a alface, o milho e o arroz, e vem causando perdas econômicas significativas no Brasil. Mesmo que as cultivares tenham alguma resistência parcial, o fungo se adapta e sob alta pressão acaba acometendo até os genótipos mais resistentes (BRESSAN \& FIGUEIREDO, 2003; RODRIGUES, 2010; BERILLI et al., 2011; SILVA, 2011; BROETTO et al., 2012; REIS et al., 2012; BONETT et al., 2013; DIAS et al., 2013; MILANESI et al., 2013; BAYER et al., 2014; RAMOS et al., 2014; SABATO \& FERNANDES, 2014).

A murcha de Fusarium além de ser predominante em regiões produtoras de feijão no Brasil vem aumentando gradualmente no centro do Brasil, como o patógeno é depositado no solo por sementes contaminadas e ainda a infecção pode ocorrer no estágio de plântula e assim não ocorre um desenvolvimento adequado e ficam enfraquecidas (TOLEDO - SOUZA et al., 2012).

Deste modo, o trabalho aqui desenvolvido teve como principal objetivo avaliar o potencial de antagonismos do Trichoderma em relação ao Fusarium in vitro em condições controladas de crescimento a acondicionamento para a possível utilização deste como fungicida em lavouras das mais diversas.

\section{MATERIAL E MÉTODOS}

O trabalho foi conduzido na Incubadora de empresas no Laboratório de Microbiologia da Universidade Federal do Tocantins - UFT campus Gurupi - TO. O Fusarium sp. e Trichoderma sp. foram adquiridos do banco de isolados do Laboratório de Produção Vegetal da Universidade Federal do Tocantins e ambos cultivados em meio de cultura Batata Dextrose Ágar (BDA). Foram utilizados 15 isolados de Trichoderma previamente codificados: UFT 86, UFT 19, UFT 111, UFT 20, UFT 33, UFT 92, UFT 24, UFT 22, UFT 80, UFT 104, UFT 48, UFT 34, UFT 79, UFT 32 e UFT 15 (Figura - 1). 
Figura - 1 Isolados de Trichodermas do banco de fungos UFT

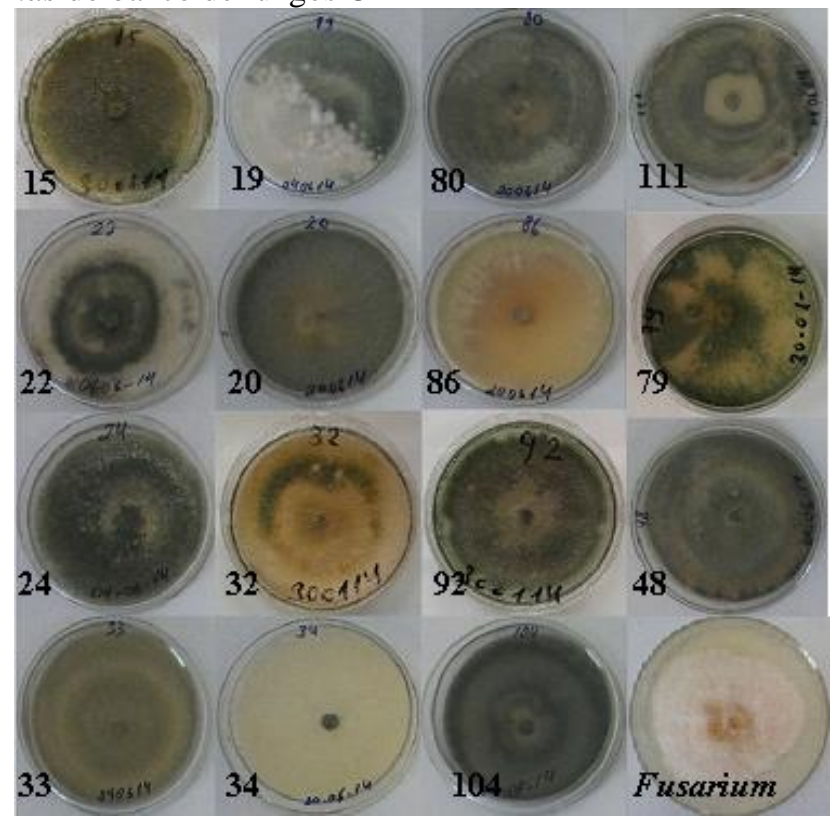

Para o confronto direto foi realizado o teste de pareamento de culturas citado por Bomfim et al. (2010), em triplicata. Para isso, foi retirado de uma placa de Petri com meio BDA, um disco de $8 \mathrm{~mm}$, de diâmetro contendo micélio

do patógeno, esse disco foi colocado a uma distância de 0,5 $\mathrm{cm}$ do bordo de uma nova placa de Petri contendo meio BDA e no outro lado da placa depositado outro disco contendo o Trichoderma (figura - 2).

Figura - 2 Placas de Petri indicando o disco do patógeno à direita e o disco do antagonista à esquerda em confronto direto

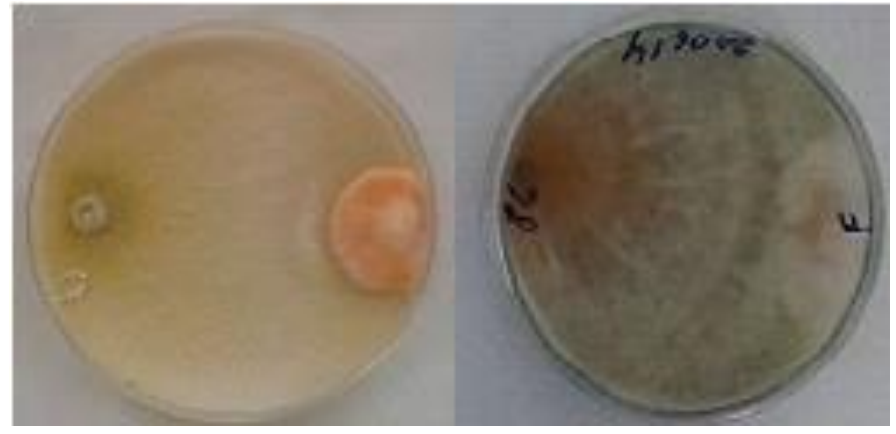

As placas assim preparadas foram incubadas por sete dias a $25^{\circ} \mathrm{C}$, em incubadora BOD com 12 horas de luz e após o período de incubação foram realizadas as medições de crescimento com paquímetro digital.

Foi realizado o teste de metabólitos voláteis baseado em Bharat et al. (1980), onde constitui a inoculação do Trichodermas e do Fusarium sp. nas tampas das placas de
Petri e após seis horas de incubação em BOD com fotoperíodo de 12 horas, uniu - se as tampas das placas de Petri o Trichoderma em baixo e o patógeno na porção superior em meio de cultura BDA. Depois da união, as tampas foram vedadas com filme PVC e incubadas por sete dias em estufa BOD aproximadamente $25^{\circ} \mathrm{C}$, com fotoperíodo de 12 horas dia (figura - 3).

Figura - 3 Técnica do antagonismo por metabólicos voláteis. 1- seleção do Trichoderma, 2 - Retirando o fundo das placas, 3 e 4 - Adaptando uma tampa na outra, 5 - Vedação com filme PVC, 6 - Incubação

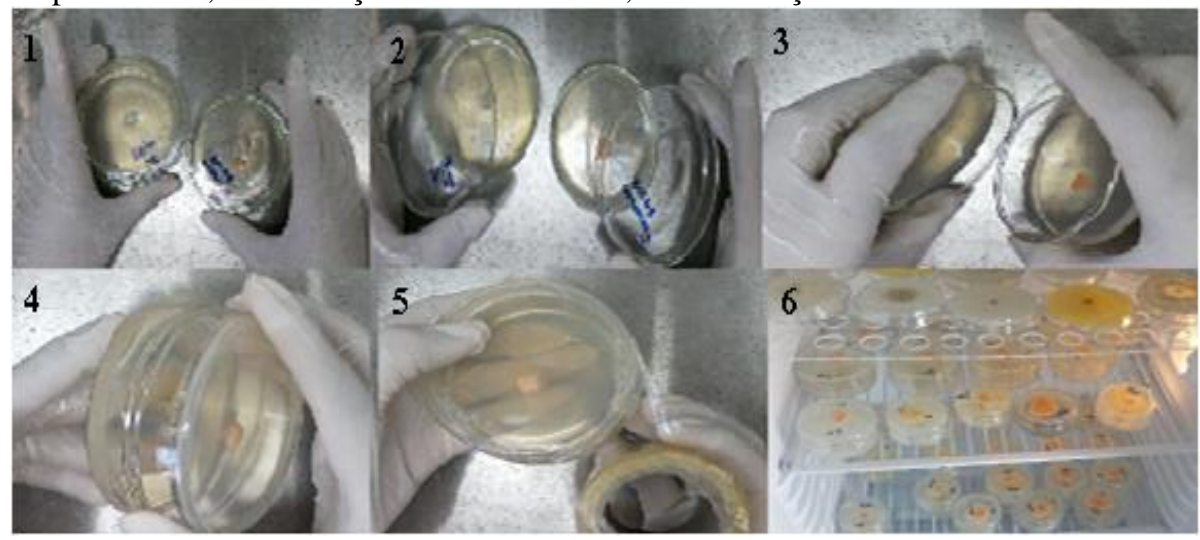


Posteriormente mediu - se o crescimento do controle e confrontando a medida desse controle com todas as medidas obtidas dos testes realizados com os 15 isolados.

\section{RESULTADO E DISCUSSÃO}

Os resultados obtidos no trabalho demonstraram que todos os isolados de Trichoderma sp. Fusarium sp. apresentaram rápido crescimento micelial em BDA. Os dados dos quinze isolados de Trichoderma, no teste de antagonismo estão dispostos na Tabela 1 .

Tabela 1. Tabela com a média do crescimento do patógeno $(\mathrm{cm})$, nota (pelo método de Bell et al. (1982), e percentagem (\%) do antagonismo em cultivo pareado dos 15 isolados de Trichoderma spp. contra Fusarium sp.

\begin{tabular}{|c|c|c|c|}
\hline IDENTIFICAÇÃO & CRESCIMENTO PATÓGENO $(\mathrm{cm})$ & NOTA & $\%$ \\
\hline UFT 86 & 0,32 & 1,0 & $94,4 \mathrm{a}$ \\
\hline UFT 19 & 1,9 & 1.5 & $87,2 \mathrm{a}$ \\
\hline UFT 111 & 1,29 & 1,5 & $84,0 \mathrm{a}$ \\
\hline UFT 20 & 1,22 & 1,5 & $83,5 \mathrm{a}$ \\
\hline UFT 33 & 1,33 & 1,5 & $82,6 \mathrm{a}$ \\
\hline UFT 92 & 1,20 & 1,5 & $82,0 \mathrm{a}$ \\
\hline UFT 24 & 1,37 & 1,5 & $81,8 \mathrm{a}$ \\
\hline UFT 22 & 2,2 & 1,5 & $81,8 \mathrm{a}$ \\
\hline UFT 80 & 1,33 & 1,5 & $81,4 \mathrm{a}$ \\
\hline UFT 104 & 1,31 & 1,5 & $81,4 \mathrm{a}$ \\
\hline UFT 48 & 1,35 & 1,5 & $81,3 \mathrm{a}$ \\
\hline UFT 34 & 1,39 & 1,5 & $81,2 \mathrm{a}$ \\
\hline UFT 79 & 3,10 & 3,5 & $48,9 \mathrm{c}$ \\
\hline UFT 32 & 3,47 & 3,5 & $44,4 \mathrm{c}$ \\
\hline UFT 15 & 3,90 & 3,5 & $38,8 \mathrm{c}$ \\
\hline
\end{tabular}

Médias seguidas pela mesma letra na coluna não diferem entre si pelo teste de Scott-Knott $(\mathrm{P}>0,01)$

Dos isolados verificados que doze deles tiveram uma ação antagonista muito agressiva e impediram o desenvolvimento do Fusarium por completo UFT 86 UFT 19 UFT 111 UFT 20 UFT 33 UFT 92 UFT 24 UFT 22 UFT 80 UFT 104 UFT 48 UFT 48.

$\mathrm{Na}$ avaliação do potencial antagônico de Trichoderma contra o Fusarium solani Louzada et al. (2009), visualizaram que $21,74 \%$ dos isolados de Trichoderma oriundo de seis estados brasileiros inibiram o crescimento do patógeno pelo teste de pareamento de culturas e praticamente metade dos isolados de Trichoderma (52\%) não apresentaram nem um efeito inibitório contra o Fusarium.

Já nos testes realizados no laboratório de microbiologia em Gurupi - TO, todos os Trichodermas apresentaram de bom a ótimo crescimento micelial descrito também em vários estudos realizados (MENOLLI JUNIOR \& PACCOLA-MEIRELLES, 2010; BOMFIM et al., 2010; MARQUES et al., 2014; SANTOS et al., 2012).

Os resultados obtidos indicam um grande potencial de controle de $F$. solani utilizando-se espécies de Trichoderma (SILVA, 2011). Nos estudos realizados por Lazarotto et al. (2012), os isolados T1 e T2 de Trichoderma $s p$. apresentaram maior potencial para controle biológico do patógeno, já que foram eficientes no antagonismo de Fusarium spp.

Com isso o controle biológico e defendido e se mostra uma alternativa promissora, sendo o Trichoderma spp. o agente de biocontrole e constitui um grande potencial de antagonismo no controle do Fusarium sp. (BETIOL \& MORANDI, 2009).

O antagonista Trichoderma apresenta características que possibilitam o seu uso em programas de controle biológico, de patógenos, sendo o mesmo incorporado ao solo junto ao substrato que serve de base alimentar e favorece a sua multiplicação ou utilizado no tratamento de sementes, contribuindo com a germinação e também como promotor de crescimento (BONETT et al., 2013).

Os resultados obtidos no presente trabalho estão de acordo com os observados por Ethur et al. (2001), onde os autores verificaram que a maioria dos isolados de Trichoderma $s p$. cresceram sobre o patógeno, apresentando nota menor 2 e indicando o potencial de Trichoderma spp. em competir por espaço e nutrientes com o $F$. oxyporum, $f$. $s p$ phaseoli.

Os mecanismos de controle biológico podem ocorrer simultaneamente ao longo do processo de vida do antagonista os quais se sobrepõem e prejudicam o desenvolvimento dos competidores (BELL, et al., 1982). Trichoderma spp. causaram a degradação das hifas hospedeiras através da secreção de metabólitos tóxicos inibindo o desenvolvimento do patógeno (MARTINSCORDER e MELO, 1998).

No confronto direto quando se estabeleceu o contato íntimo entre as hifas, o antagonista enrolou-se no hospedeiro, formando estruturas semelhantes a ganchos, causando a destruição da parede celular, provavelmente para 
obter nutrientes a partir das células mortas (MACHADO, 2009).

O crescimento de Trichoderma spp. foi bastante agressivo, conferindo a esses antagonistas uma enorme capacidade como competidores através da rápida colonização do substrato (MARTINS-CORDER \& MELO, 1998; CARISSIMI, 2006; DIAS et al., 2013; AULER et al., 2013).

Segundo Ethur em 2006, o principal problema do teste de controle biológico é encontrar o antagonista ideal e em seus estudos confirma que para o Fusarium sp. seria o Trichoderma. Milanesi et al. (2013), apresentam que os isolados de Trichoderma spp. tem maior capacidade antagônica do solo rizosférico de genótipos de soja com sintomas de Síndrome da Morte Súbita infectado de Fusarium spp. e podem ser utilizados em testes à campo para verificar se o antagonismo é mantido e buscar o controle biológico da doença.

Para o teste de produção de metabólitos voláteis, verificou-se que os 15 isolados selecionados apresentaram diferenças significativa em relação ao controle. Estes dados estão dispostos na Tabela 2.

Tabela 2. Média de porcentagem (\%) do efeito inibidor de metabólitos voláteis de Trichoderma sp. sobre um crescimento de fusarium $\mathrm{sp}$.

\begin{tabular}{cc}
\hline IDENTIFICAÇÃO & $\%$ \\
\hline UFT 79 & $55,68 \mathrm{a}$ \\
UFT 104 & $52,94 \mathrm{a}$ \\
UFT 32 & $52,4 \mathrm{a}$ \\
UFT 92 & $51,74 \mathrm{a}$ \\
UFT 86 & $51,35 \mathrm{a}$ \\
UFT 80 & $50,12 \mathrm{a}$ \\
UFT 48 & $49,91 \mathrm{a}$ \\
UFT 34 & $49,4 \mathrm{a}$ \\
UFT 24 & $48,8 \mathrm{a}$ \\
UFT 22 & $47,4 \mathrm{a}$ \\
UFT 32 & $44,96 \mathrm{a}$ \\
UFT 19 & $39,7 \mathrm{~b}$ \\
UFT 20 & $38,72 \mathrm{~b}$ \\
UFT 111 & $34,02 \mathrm{~b}$ \\
UFT 15 & $29,75 \mathrm{~b}$ \\
Fusarium sp. & $0,00 \mathrm{c}$ \\
\hline
\end{tabular}

Médias seguidas pela mesma letra na coluna não diferem entre si pelo teste de Scott-Knott $(\mathrm{P}>0,01)$

Empregou-se como critério de seleção o potencial para produção de metabólitos, a velocidade para colonizar o substrato e o fato de ter pelo menos dois isolados da mesma espécie. Apesar dos antibióticos apresentarem grande importância no antagonismo, a competição é um mecanismo essencial em condições naturais (MARTINS CODER \& MELO, 1998).

Quanto à produção de metabólitos voláteis, os isolados de Trichoderma sp. testados exibiram ação antifúngica, não diferiram entre si e o valor médio de porcentagem de inibição ficou próximo a de $50 \%$ entre os isolados. Carvalho et al. (2011), corroboram com presente trabalho pois em seus ensaios o grupo de Trichodermas testados tem a capacidade de produzir metabólitos tóxicos com efeito antifúngico ou fungistático.

Os antibióticos voláteis atuam sobre os fungos suscetíveis através da inibição do crescimento micelial e que isolados com capacidade para produzirem substâncias não voláteis nem sempre produzem substâncias voláteis (DILDEY et al., 2014).

\section{CONCLUSÕES}

Os antagonistas selecionados no presente estudo são produtores de metabólitos voláteis.

Dos 15 isolados de Trichoderma sp. menos de $20 \%$ inibiram o crescimento do patógeno Fusarium sp. abaixo de $50 \%$ em contra partida $80 \%$ dos isolados de Trichoderma $s p$. inibiram completamente crescimento dos patógeno em mais de $81 \%$ do crescimento.

Todos os isolados de Trichoderma sp. pelo método de metabólitos voláteis diminuíram significativamente o crescimento micelial do patógeno testado.

\section{REFERÊNCIAL BIBLIOGRÁFICO}

ANDRADE, G.; NOGUEIRA, M. A. Bioindicadores para uma análise de risco ambiental. Biotecnologia Ciência e Desenvolvimento, n. 34, p. 13 - 21, 2005.

AUler, A. C. V.; CARVAlho, D. D. C.; Mello, S. C. M. Antagonismo de trichoderma harzianum a sclerotium rolfsii nas culturas do feijoeiro e soja. Revista Agro@mbiente, v. 7, n. 3, p. 359 -365, 2013.

BAYER, T.; LOECK, A. E.; GUERRERO, M. F. C.; ELIAS, M. C. Aplicação aérea de fungicidas com diferentes equipamentos e volumes sobre a produtividade, qualidade de grãos e controle de doenças em arroz irrigado. Ciência Rural, v. 44, n. 8, p.1377 - 1383, 2014.

BELL, D. K.; WELLS, H. D.; MARKHAM, C. R. In vitro antagonism of trichoderma species against six fungal plant pathogens. Phytopathology, v. 72 , p. $379-382$, 1982.

BERILLI, S. S.; ALMEIDA, S. B.; CARVALHO, A. J. C.; FREITAS, S. J.; BERILLI, A. P. C. G.; SANTOS, P. C. Avaliação sensorial dos frutos de cultivares de abacaxi para consumo in natura. Revista Brasileira De Fruticultura, v.33, n. 1, p. 592 - 598, 2011.

BETIOL, W.; MORANDI M. A. B. Biocontrole de doenças e plantas: uso e perspectivas. EMBRAPA meio ambiente, p. 239, 2009.

BHARAT, R.; SINGH, V. N.; SINGH, D. B. Trichoderma viride as a mycoparasite of aspergillus spp.. Plant and Soil, v. 57, p. 131 - 135, 1980.

BOMFIM, M. P.; SÃO JOSÉ, A. B.; REBOUÇAS, T. N. H.; ALMEIDA, S. S. DE.; SOUZA, I. V. B.; DIAS, N. O. Avaliação antagônica in vitro e in vivo de trichoderma spp. a rhizopus stolonifer em maracujazeiro amarelo. Summa Phytopathologica, v. 36, n. 1, p.61 - 67, 2010. 
BONETT, L. P.; CORRÊA, M. S. G.; POZZA-JÚNIOR, M. C.; ROSA, T. B.; SILVA, L. I. Antagonismo in vitro de trichoderma spp. contra agente causal da antracnose em feijoeiro comum. SaBios. Rev. Saúde e Biol., v. 8, n. 1, p. $27-35,2013$.

BORÉM, A. A. História da biotecnologia. Biotecnologia Ciência e Desenvolvimento, n. 34, p. 10 - 12, 2005.

BRASIL - Ministério da Ciência, Tecnologia e Inovação (MCTI). Estratégia nacional de ciência, tecnologia e inovação 2012 - 2015. Balanço das atividades estruturantes 2011. 2012.

BRESSAN, W.; FIGUEIREDO, J. E. F. Controle de fusarium moniliforme em sementes de milho por actinomicetos. Ministério da Agricultura Pecuária e Abastecimento EMBRAPA - milho e sorgo, 2003.

BROETTO, L.; PAZDIORA, P. C.; RAVAGNANI, L. K.; MEINERZ, C. C. M.; COLTRO, S.; KUHN, O. J. Avaliação in vitro de isolados de trichoderma sp. no controle de fusarium sp. do milho. In: XXIX Congresso Nacional de Milho e Sorgo, 2012.

Carissimi, M. Estudo da atividade antifúngica de bacillus e164 contra biopolaris sorokiniana. Porto Alegre: UFRS, 2006. Dissertação Mestrado.

CARVALHO, D. D. C.; MELLO, S. C. M.; LOBO JÚNIOR, M.; SILVA, M. C. Controle de fusarium oxysporum $f$. sp. phaseoli in vitro e em sementes, e promoção do crescimento inicial do feijoeiro comum por trichoderma harzianum. Tropical Plant Pathology, v. 36, n. 1, 2011.

DIAS, P. P.; BERBARA, R. L. L.; FERNANDES, M. C. A. Controle de rhizoctonia solani e fusarium oxysporum f.sp. phaseoli por biopreparados de isolados de trichoderma spp.. Summa Phytopathologica, v. 39, n. 4, p. $258-262,2013$.

DILDEY, O. D. F.; BARBIAN, J. M.; GONÇALVES, E. D. V.; BROETTO, L.; ETHUR, L. Z.; KUHN, O. J.; BONETT, L. P. Inibição do crescimento in vitro de sclerotinia sclerotiorum, causador de mofo branco, por isolados de trichoderma spp.. Revista brasileira biociência, v. 12, n. 3, p. 132 - 136, 2014.

EDEL, V.; STEINBERG, C.; GAUTHERON, N.; ALABOUVETTE, C. Populations of non - pathogenic fusarium oxysporum associated with roots of four plant species compared to soil borne populations. Phytopathology, St. Paul, v. 87, p. 693 - 697, 1997.

EMBRAPA SOJA, tecnologias de produção de soja região central do Brasil. Produção de Soja Região Central do Brasil, n. 1, 2004.

EMBRAPA Mandioca e Fruticultura Tropical. Manejo integrado da fusariose do abacaxizeiro. Mandioca e Fruticultura Tropical, n. 32, 2005.
EMBRAPA RORAIMA Sistemas de produção, versão eletrônica, Cultivo de Soja no Cerrado de Roraima. $1^{\text {a }}$ ed. v. $1,2009$.

ETHUR, L. Z.; CEMBRANEL, C. Z.; SILVA, Da A. C. F. Seleção de trichoderma spp. visando ao controle de sclerotinia sclerotiorum, in vitro. Ciência Rural, v. 31, n. 5 , p. $885-887,2001$.

ETHUR, L. Z. Dinâmica Populacional e Ação de Trichoderma no Controle de Fusariose em Mudas de Tomateiro e Pepineiro. Santa Maria: USM, 2006. Tese Doutorado.

FISCHER, N. L.; BURGUESS, L. W.; TOUSSOUN, T. A.; NELSON, P. E. Carnation leaves as a substrate and for preserving cultures of fusarium species. Phytopathology, v. 72 , p. $151-153,1982$.

FREITAS, M. M. Aspectos gerais e morfológicos de trichoderma sp. estudos em doenças de plantas. IFGoiano câmpus Urutaí, 2010. http://fitopatologia1.blogspot.com.br/2010/11/descricaomicologica-aspectos-gerais-e_2802.html. 27 OUT. 2014.

GRIGOLETTI JUNIOR, A; SANTOS, A. F; AUER C. G. Perspectiva do uso do Controle Biológico Contra Doenças Florestais. Embrapa Florestas, Fuepf, v. 30, n. 1, p. $155-165,2000$.

HARMAN, G. E.; HOWELL, C. R.; VITERBO, A.; CHET, I.; LORITO, M. Trichoderma species - opportunistic, avirulent plant symbionts. Natural Reviews. Microbiology, v.2, p. 43 - 56, 2004.

HOOG, G. S.; GUARRO, J.; GENE J.; FIGUEIRAS, M. J. Centraalbureau voor schimmelcultures/ universitat rovira i vigili. Atlas of clinical fungi, 2000.

JESUS, E. P.; SOUZA, C. H. E.; POMELLA, A. W. V.; COSTA, R. L.; SEIXAS, L. SILVA, R. B. Avaliação do potencial de trichoderma asperellum como condicionador de substrato para a produção de mudas de café. Revista do Centro Universitário de Patos de Minas, v. 2, p. $7-19,2011$.

LAZAROTTO, M.; BOVOLINI, M. P.; MACIEL, C. G.; MUNIZ, M. F. B. Seleção in vitro de Isolados de Trichoderma spp. com Potencial de Antagonismo a Isolados Patogênicos de Fusarium spp. In: XVI Simpósio De Ensino, Pesquisa E Extensão, Unifra, v. 3, 2012.

LOUZADA, G. A. S.; CARVALHO, D. D. C.; MELLO, S. C. M.; LOBO JÚNIOR, M.; MARTINS, I.; BRAÚNA, L. M. Antagonist potential of trichoderma spp. from distinct agricultural ecosystems against sclerotinia sclerotiorum and fusarium solani. BiotaNeotropica, v. 9, n. 3, p. $145-149,2009$.

MACHADO, M. A. B. L. Isolamento, caracterização e avaliação da atividade antimicrobiana de fungos endofíticos de caesalpinia echinata lam. (leguminosae- 
caesalpinioideae). Maceió: UFAL, 2009. Tese Doutorado.

MARQUES, H. I. P.; SILVA, M. B.; MARQUES, M. D. P.; RODRIGUES, R. C.; RIBEIRO, P. R. C. C. Inibição do crescimento micelial de trichoderma harzianum por fertilizantes líquidos. Enciclopédia Biosfera, v. 10, n. 18, p. 2040, 2014.

MARTINS - CORDER, M. P.; Melo, I. S. Antagonismo in vitro de trichoderma spp. A verticillium dahliae kleb. Scientia agrícola, v. 55, n. 1, 1998.

MARTINS, L. S. Biotecnologia e agricultura no Brasil contemporâneo. Revista da UFG, v. 7, n. 1, 2004.

MELLO, S. C. M.; SILVA, J. B. T. Utilização de trichoderma no controle de fungos fitopatogênicos. Embrapa Recursos Genéticos e Biotecnologia, 2007.

MENOLLI JUNIOR, N.; PACCOLA-MEIRELLES, L. D. Obtenção de linhagens de lentinula edodes resistentes a temperaturas elevadas e seleção de linhagens resistentes ao trichoderma sp.. Cincas Agrotecnológica, v. 34, n. Especial, p. 1640 - 1646, 2010.

MILANESI, P. M.; BLUME, E.; MUNIZ, M. F. B.; REINIGER, L. R. S.; ANTONIOLLI, Z. I.; JUNGES, E.; LUPATINI, M. Detecção de fusarium spp. e trichoderma spp. e antagonismo de trichoderma sp. em soja sob plantio direto. Semina: Ciências Agrárias, v. 34, n. 6, suplemento 1, p. 3219 - 3234, 2013.

OLIVEIRA, A. G.; CHAGAS JUNIOR, A. F.; SANTOS, G. R.; MILLER, L. O.; CHAGAS, L. F. B. Potencial de solubilização de fosfato e produção de aia por trichoderma spp.. Revista Verde de Agroecologia e Desenvolvimento Sustentável, v. 7, n. 3, 2012.

OMS - World Health Organization. Global strategy on diet, physical activity and health. Geneva. Proceedings, 2004.

Peres, F.; Moreira, J. C.; Claudio, L. Os impactos dos agrotóxicos sobre a saúde e o ambiente. Ciência \& Saúde coletiva, v.12, n. 4, 2007.

PESSANHA, L. D. R.; WILKIINSON, J. C. Cadernos de ciência e tecnologia. Empresa Brasileira de Pesquisa Agropecuária, v. 20, n. 2, p. 263 - 303, 2003.

RAMOS, D. P.; BARBOSA, R. M.; VIEIRA, B. G. T. L.; PANIZZI, R. C.; VIEIRA, R. D. Infecção por fusarium graminearum e fusarium verticillioides em sementes de milho. Pesquisa Agropecuária Tropical, v. 44, n. 1, p. 24 $-31,2014$.
REIS, E. F.; PELISSARI, A.; MORAES, A.; OLIVEIRA, E. B.; RUARO, L. Podridão-vermelha-da-raiz da soja em cultivos com diferentes sistemas de manejo e coberturas do solo. Pesquisa Agropecuária Brasileira, v. 47, n. 4, p. $528-533,2012$

RODRIGUES, J. Trichoderma spp. associado a níveis de adubação npk no patossistema sclerotinia sclerotiorum feijoeiro. Santa Maria: UFRS, 2010. Dissertação Mestrado.

SABATO, E. O.; FERNANDES, F. T. Doenças do milho (zea mays l.). Sociedade brasileira de fitopatologia. EMBRAPA - Milho e Sorgo, 2014.

SANTIN, M. C. R. Potencial do uso de fungos trichoderma spp. e paecilomyces lilacinus no biocontrole de meloidogyne incógnita em phaseolus vulgaris. PortoAlegre: UFRS, 2008. Tese Doutorado.

SANTOS, C. C.; DE OLIVEIRA, F. A.; DOS SANTOS, M. S.; TALAMINI, V.; FERREIRA, J. M. S.; DOS SANTOS, F. J. Influência de trichoderma spp. sobre o crescimento micelial de thielaviopsis paradoxa. Scientia Plena, v. 8, n. 4, 2012.

SILVA, A. N. Efeito de Produtos Químicos e de Trichoderma Spp. no Controle de Fusarium Solani do Maracujazeiro. 2011. Dissertação (Mestrado em Agronomia, Área de concentração em Fitotecnia) - Universidade Estadual do Sul da Bahia de Vitória da Conquista - BA.

SILVA, D. P.; GELLEN, L. F. A.; CHAGAS JÚNIOR, A. F.; SCHEIDT, G. N. Potencial de produção de lipases e fosfolipases por trichoderma_harzianum para a indústria de alimentos. Evidência interdisciplinar, v. 14, n. 1, p. 69 $-78,2014$.

TOCANTINS, Agricultura. Portal de informações e serviços. 2011. http://portal.to.gov.br/empresario/agricultura/448. 27 OUT. 2014

TOLEDO - SOUZA, E. D.; SILVEIRA, P. M.; CAFÉ FILHO, A. C.; LOBO JUNIOR, M. Fusarium wilt incidence and common bean yield according to the preceding crop and the soil tillage system. Pesquisa Agropecuária Brasileira, v. 47, n. 8, p. 1031 - 1037, 2012. 